\title{
The mycotoxin deoxynivalenol promotes uptake of Salmonella Typhimurium in porcine macrophages, associated with ERK1/2 induced cytoskeleton reorganization
}

\author{
Virginie Vandenbroucke ${ }^{1 *}$, Siska Croubels ${ }^{1}$, Elin VerbrugGhe ${ }^{2}$, Filip Boyen ${ }^{2}$, \\ Patrick De Backer ${ }^{1}$, Richard Ducatelle ${ }^{2}$, Ivan Rychlik ${ }^{3}$, Freddy HaesebroucK ${ }^{2}$, \\ Frank PASMANS ${ }^{2}$ \\ ${ }^{1}$ Department of Pharmacology, Toxicology and Biochemistry, Faculty of Veterinary Medicine, Ghent University, \\ Salisburylaan 133, 9820 Merelbeke, Belgium \\ ${ }^{2}$ Department of Pathology, Bacteriology and Avian Diseases, Faculty of Veterinary Medicine, Ghent University, \\ Salisburylaan 133, 9820 Merelbeke, Belgium \\ ${ }^{3}$ Department of Bacteriology, Laboratory of Salmonella infections, Veterinary Research Institute, Hudcova 70, \\ 61200 Brno, Czech Republik
}

(Received 15 January 2009; accepted 11 August 2009)

\begin{abstract}
Both the mycotoxin deoxynivalenol (DON) and Salmonella Typhimurium are major issues in swine production. This study aimed at examining the interaction between DON and Salmonella Typhimurium at the level of the porcine innate immune system, represented by macrophages. First, we assessed the direct cytotoxic effect of DON on porcine macrophages. Incubation with $0.25 \mu \mathrm{g} / \mathrm{mL}$ of DON or higher resulted in a significant cytotoxic effect after $24 \mathrm{~h}$ of incubation. Secondly, the direct toxic effect of DON on the growth and on the expression of Salmonella pathogenicity island 1 (SPI-1) and SPI-2 virulence genes of Salmonella Typhimurium was determined. At low non-cytotoxic concentrations, as can be found in the serum of pigs, DON did not have any effect on either growth or virulence gene expression of Salmonella Typhimurium. However, when the invasion and intracellular survival of Salmonella Typhimurium in macrophages preexposed to $0.025 \mu \mathrm{g} / \mathrm{mL}$ of DON was examined, DON significantly promoted the uptake of Salmonella Typhimurium into macrophages. The enhanced uptake coincided with marked F-actin reorganization of the cells, which was due to the activation of extracellular signal-regulated protein kinase 1/2 (ERK1/2). These results suggest that low but relevant concentrations of DON modulate the innate immune system and could thus increase the susceptibility of pigs to infections with Salmonella Typhimurium.
\end{abstract}

\section{deoxynivalenol / Salmonella Typhimurium / pig / macrophage / cytoskeleton}

\section{INTRODUCTION}

In the northern temperate regions the mycotoxin deoxynivalenol (DON) is one of the most frequent contaminants of maize and small grain

\footnotetext{
* Corresponding author: virginie.vandenbroucke@ ugent.be
}

cereal [4]. This contamination of cereal crops in the field is seen under low temperature and high humidity conditions. If critical concentrations of DON in diets for farm animals are exceeded, the health, growth and reproductive performance of animals may be impaired [11]. The toxic effects of DON have been well documented and among farm animals, pigs seem to 
be particularly sensitive to the dietary intake of DON. DON has been associated with symptoms varying from partial feed refusal and decreased feed intake at feed concentrations as low as $1-2 \mathrm{mg} / \mathrm{kg}$ feed, to vomiting and complete feed refusal at concentrations of more than $20 \mathrm{mg} / \mathrm{kg}$ feed [22, 34]. Substantial economic losses have therefore been attributed to DON contamination of pig feed [2].

The mechanism of toxicity for trichothecenes, to which DON belongs, is complex, but the biochemical basis is non-competitive inhibition of different steps in the protein synthesis by interfering with peptidyl transferase at the active site on ribosomes [8]. However, many of their toxic effects might also be related to a rapidly ensuing dysregulation of intracellular cell signaling and consequent alterations in downstream gene expression [27]. Exposure to low levels of trichothecenes appears to promote expression of a diverse array of cytokines and proinflammatory genes in vitro and in vivo via a mechanism known as the ribotoxic stress response that involves multiple intracellular signaling cascades [26, 38, 39]. Trichothecenes such as DON are also known to rapidly activate mitogen-activated protein kinase (MAPK) via a process termed the "ribotoxic stress response". These MAPK modulate numerous physiological processes including cell growth, differentiation and apoptosis and are crucial for the signal transduction in the immune response. The members of the MAPK family can be classified into three subfamilies: ERK/MAPK, p38 and JNK. Yang et al. [37] described that DON induces p21 mRNA stability in terms of interaction with RNA-binding proteins extracellular signal-regulated protein kinase 1/2 (ERK1/2) activation. P21 activated kinases (PAK) are known to modulate cell morphology, actin/ microtubule dynamics and cell motility [3] whereas ERK is able to phosphorylate several target proteins in the cytoplasm including cytoskeletal proteins. In contrast to these stimulatory effects, high doses of trichothecenes promote rapid onset of leucocyte apoptosis and this will be manifested as immunosuppression [26].

In European countries, Salmonella enterica subspecies enterica serovar Typhimurium (Salmonella Typhimurium) is the predominant serovar isolated from pigs which most often carry the bacterium without obvious symptoms $[7,15]$. These carrier pigs, however, play an important role as a source of contamination for the environment and for other animals and after slaughter, their carcasses can be a source of contamination for other carcasses in the slaughter facility [13]. Macrophages play an important role in the pathogenesis of Salmonella infections in pigs as the bacteria are able to survive and even multiply intracellularly after bacterial entry into the cells. Macrophage invasion coincides with membrane ruffles, bacterium uptake and formation of Salmonella containing vacuole [17, 25]. Two major virulence determinants of Salmonella Typhimurium are the Salmonella pathogenicity island 1 (SPI-1) for invasion and SPI-2 for intracellular proliferation [7, 24]. Two major regulators for the SPI-1 or SPI-2 gene expression are respectively HilA and SsrA.

Several studies describe an increased susceptibility to experimental or natural mucosal infections after the ingestion of some mycotoxins [18, 32, 33]. Hara-Kudo et al. [21] examined the effects of DON on Salmonella Enteritidis infection in mice and suggested that administration of $2 \mathrm{mg} / \mathrm{L} \mathrm{DON}$ in the drinking water reduced resistance to peroral infection of Salmonella Enteritidis presumably by inhibiting the cell-mediated immune function. However, until now there are no data available describing a possible interaction between DON and the pathogenesis of a Salmonella Typhimurium infection in pigs. The aim of the present study was to examine the effect of DON on the interaction of Salmonella Typhimurium with porcine macrophages, at low DON levels that are not cytotoxic and do not impair Salmonella growth and virulence gene expression.

\section{MATERIALS AND METHODS}

\subsection{Chemicals}

DON, ERK1/2 inhibitor (U0126 ethanolate) [14], ERK1/2 activator phorbol myristate acetate (PMA) [10] and dimethyl sulfoxide (DMSO) were purchased from Sigma-Aldrich (St. Louis, MO, USA). DON 
stock solution of $4 \mathrm{mg} / \mathrm{mL}$ was prepared in anhydrous methanol and stored at $-20{ }^{\circ} \mathrm{C}$. Serial dilutions of DON were, depending on the experiment, prepared in Luria-Broth (LB, Sigma-Aldrich, Steinheim, Germany) or in the corresponding cell medium allowing the addition of similar volume of vehicle in all experiments. Macrophages seeded onto 24-well or 96-well plates were treated with selected concentrations of DON or equivalent volumes of medium (untreated cells). The ERK1/2 inhibitor U0126 ethanolate was dissolved in DMSO leading to a $3 \mathrm{mM}$ stock solution and stored at $-20^{\circ} \mathrm{C}$. For experiments, U0126 ethanolate was diluted in the corresponding cell medium to a final concentration of $10 \mu \mathrm{M}$. The PMA stock solution was prepared by dissolving $5 \mathrm{mg}$ of PMA in $1 \mathrm{~mL}$ of ethanol and stored in small aliquots at $-20{ }^{\circ} \mathrm{C}$. Prior to use, the stock solution was further diluted in the corresponding cell medium to a final concentration of $50 \mathrm{ng} / \mathrm{mL}$.

\subsection{Bacterial strains and growth conditions}

Salmonella enterica subspecies enterica serovar Typhimurium (Salmonella Typhimurium) strain 112910a was used as the wild type (WT) strain in which all mutant strains were constructed. To obtain highly invasive late logarithmic cultures for invasion assays [23], $2 \mu \mathrm{L}$ of a stationary phase culture was inoculated in $5 \mathrm{~mL} \mathrm{LB}$ and grown for $5 \mathrm{~h}$ at $37^{\circ} \mathrm{C}$ without aeration. The construction and characterization of a deletion mutant in the gene encoding the SPI-1 translocator/effector protein SipB has been described before [5]. Salmonella Typhimurium strains carrying the plasmid containing either the hilA-luxCDABE or the ssrA-luxCDABE transcriptional fusions were used in the virulence gene expression experiments [5]. For fluorescence microscopy, the pFPV25.1 plasmid expressing green fluorescent protein under the constitutive promoter of rpsM was used $[6,35,36]$.

\subsection{Isolation of porcine pulmonary alveolar macrophages}

Porcine pulmonary alveolar macrophages (PAM) were isolated by broncho-alveolar washes from lungs of euthanized 3 to 4 week old piglets, obtained from a Salmonella-negative farm, as described previously [12]. The isolated cells were pooled and frozen in liquid nitrogen until further use. Prior to seeding the PAM, frozen aliquots of approximately $10^{7}$ cells $/ \mathrm{mL}$, were thawed in phosphate-buffered saline (PBS) with $10 \%$ fetal calf serum (FKS, Hyclone, Cramlington,
England, UK) at $4{ }^{\circ} \mathrm{C}$. Cells were washed 3 times in PBS and cultured in RPMI (Gibco, Life Technologies, Paisley, Scotland, UK) containing $2 \mathrm{mM} \mathrm{L-glutamine}$ (Gibco) and $1 \mathrm{mM}$ sodium pyruvate (Gibco).

\subsection{Cytotoxicity assays}

The Cell Proliferation Reagent WST-1 kit from Roche Applied Science (Bazel, Switzerland) was used to assess the direct cytotoxic effect of DON on PAM. The test was used according to the manufacturer's instructions. The absorbance of DONtreated wells was measured at $450 \mathrm{~nm}$ using a microplate ELISA reader (Multiscan MS, Thermo Labsystems, Helsinki, Finland) and compared with a solvent-treated control. The percentages of DON induced cytotoxicity were calculated using the following formula

$$
\% \text { cytotoxicity }=100 \times \frac{(c-b)-(a-b)}{(c-b)} .
$$

In this formula $a=\mathrm{OD}_{450}$ derived from the wells incubated with DON, $b=\mathrm{OD}_{450}$ derived from blank wells, $c=\mathrm{OD}_{450}$ derived from untreated control wells.

In addition to the WST-1 assay, the lactate dehydrogenase cytotoxicity detection kit (LDH, Roche Applied Science) was used to measure cytotoxicity and cell lysis by detecting LDH activity released from damaged cells. The test was used in accordance to the manufacturer's instructions and an ELISA plate reader at $492 \mathrm{~nm}$ was used to measure the absorbance.

\subsection{Effect of DON on the growth and on SPI-1 and SPI-2 virulence gene expression of Salmonella Typhimurium}

The effect of concentrations of DON from 0.005 to $20 \mu \mathrm{g} / \mathrm{mL}$ on Salmonella Typhimurium WT was examined during $24 \mathrm{~h}$ in order to detect a direct toxic effect on the growth of the bacteria. Therefore, Salmonella Typhimurium was grown overnight in $\mathrm{LB}$ with aeration at $37{ }^{\circ} \mathrm{C}$ after which a suspension of the bacteria (Mc Farland 0.5) was added to the different concentrations of DON in a 96-well plate. The plate was incubated at $37{ }^{\circ} \mathrm{C}$ and after $24 \mathrm{~h}$ of incubation, the number of cfu $/ \mathrm{mL}$ was determined by titration. This step was carried out by making 10 -fold dilutions of $20 \mu \mathrm{L}$ of the bacterial suspensions. Then six $20 \mu \mathrm{L}$ samples of each dilution were inoculated on Brilliant Green agar (BGA) and incubated for $24 \mathrm{~h}$ at $37^{\circ} \mathrm{C}$ after which the colonies were counted. 
A FluoroScan Ascent fluorometer (ThermoLabsystems) was used to quantify SPI-1 and SPI-2 expression of Salmonella Typhimurium by measuring the light production (luminescence) of Salmonella Typhimurium strains carrying the plasmids containing either the hilA-lux CDABE or the ssrA-lux CDABE transcriptional fusions. Bacterial cultures were grown in microplates in $200 \mu \mathrm{L}$ of LB medium supplemented with the different concentrations of DON and in non-supplemented LB medium at $37{ }^{\circ} \mathrm{C}$. Light production was measured every 15 min during $24 \mathrm{~h}$ and expressed as the relative gene expression.

\subsection{Invasion and intracellular survival assays}

To examine whether the ability of Salmonella Typhimurium and its isogenic $\operatorname{sip} B$ mutant to invade and proliferate in PAM was altered after preexposure of the macrophages to DON, invasion and intracellular survival assays were performed. Therefore, PAM were seeded in 24-well plates at a density of approximately $5 \times 10^{5}$ cells per well and were allowed to attach for at least $2 \mathrm{~h}$. These wells were exposed to different non-cytotoxic concentrations of DON $(0.005-0.100 \mu \mathrm{g} / \mathrm{mL})$. After $24 \mathrm{~h}$, the wells were rinsed and inoculated with Salmonella Typhimurium at a multiplicity of infection (moi) of 10:1. To synchronize the infection, the inoculated multiwell plates were centrifuged at $365 \mathrm{~g}$ for $10 \mathrm{~min}$. After $30 \mathrm{~min}$ incubation at $37^{\circ} \mathrm{C}$ under $5 \% \mathrm{CO}_{2}$, the wells were rinsed and fresh medium supplemented with $50 \mu \mathrm{g} / \mathrm{mL}$ gentamicin (Gibco) was added for $1 \mathrm{~h}$. For the invasion assay the PAM were lysed with $1 \%(\mathrm{v} / \mathrm{v})$ Triton-X (Sigma-Aldrich) for $10 \mathrm{~min}$ and 10 -fold dilutions were plated on BGA plates. To assess intracellular growth, the medium containing $50 \mu \mathrm{g} / \mathrm{mL}$ gentamicin was replaced after $1 \mathrm{~h}$ incubation with fresh medium supplemented with 10 $\mu \mathrm{g} / \mathrm{mL}$ gentamicin and the number of viable bacteria was assessed $6 \mathrm{~h}$ after infection as described above. All measurements were performed in triplicate and the experiment was carried out on three independent occasions.

To visualize the effect of DON on the number of cell-associated Salmonella bacteria, PAM were seeded in sterile Lab-tek ${ }^{\circledR}$ chambered coverglasses (VWR, Leuven, Belgium) and exposed to $0.025 \mu \mathrm{g} / \mathrm{mL}$ of DON in cell medium or to cell medium only for $24 \mathrm{~h}$ at $37{ }^{\circ} \mathrm{C}$. Subsequently the invasion and proliferation assay was performed as described before after inoculation with green fluorescent protein (gfp)-producing Salmonella. Cells were washed three times to remove unbound bacteria. Cell trace ${ }^{\circledR}$ calcein red-orange (Molecular Probes Europe, Leiden, The
Netherlands) was added for $30 \mathrm{~min}$ at $37{ }^{\circ} \mathrm{C}$. Afterwards, cells were washed three times with PBS and fluorescence microscopy was carried out. In 100 macrophages, the number of macrophages containing gfpSalmonella was counted and the average number of cell-associated bacteria was calculated.

\subsection{Morphological changes in macrophages}

Staining techniques were performed to visualize possible morphological changes in macrophages exposed to DON in order to explain the observed difference in uptake of Salmonella Typhimurium in macrophages whether or not exposed to DON.

\subsubsection{Haemacolor staining}

PAM were seeded onto 13-mm-circular glass slides (VWR) in a 24-well plate at a concentration of $1 \times 10^{6}$ cells $/ \mathrm{mL}$ and were incubated at $37{ }^{\circ} \mathrm{C}$ in $5 \% \mathrm{CO}_{2}$ for at least $2 \mathrm{~h}$. Subsequently, either $0.025 \mu \mathrm{g} / \mathrm{mL}$ of DON or cell medium was added. After incubation of $24 \mathrm{~h}$ at $37{ }^{\circ} \mathrm{C}$ in $5 \% \mathrm{CO}_{2}$, cells were washed three times with PBS containing $\mathrm{Ca}^{2+}$ and $\mathrm{Mg}^{2+}$ (PBS+) and stained with Haemacolor ${ }^{\circledR}$ stain (Merck, Darmstadt, Germany). Glass slides were mounted with coverslips and observed microscopically in at least three time-independent assays. Attention was paid to cellular and nuclear changes with special focus on changes of the cell membrane, presence of membrane ruffles and apoptotic changes in the nucleus.

\subsubsection{Staining of F-actin with phalloidin-Texas $\operatorname{Red} X^{\circledast}$}

PAM were seeded onto 13-mm-circular glass slides in a 24-well plate at a concentration of $1 \times 10^{6}$ per mL. After $2 \mathrm{~h}$ of incubation, the cells were exposed to cell medium, $0.025 \mu \mathrm{g} / \mathrm{mL}$ of DON, $10 \mu \mathrm{M}$ of the ERK1/2 inhibitor U0126 ethanolate in combination with $0.025 \mu \mathrm{g} / \mathrm{mL}$ DON or $50 \mathrm{ng} / \mathrm{mL}$ of the ERK1/2 activator PMA for $24 \mathrm{~h}$ at $37{ }^{\circ} \mathrm{C}$ in $5 \% \mathrm{CO}_{2}$. PAM exposed to cell medium served as negative control. Thereafter, they were gently washed twice with $0.5 \mathrm{~mL}$ PBS + at $37^{\circ} \mathrm{C}$, fixed with $0.5 \mathrm{~mL} 3.0 \%$ paraformaldehyde for $10 \mathrm{~min}$ at room temperature, gently washed again with $0.5 \mathrm{~mL}$ PBS+ and then permeabilized with $0.5 \mathrm{~mL} 0.1 \%$ Triton X-100 in PBS+ for $2 \mathrm{~min}$ at room temperature. Following washing with $\mathrm{PBS}+$, $0.25 \mathrm{~mL}$ phalloidin-Texas Red $\mathrm{X}^{\circledR}$ (Molecular Probes, Eugene, Oregon, USA) (1:100 in PBS+) was added to each well and the 24-well plate was 
incubated at $37{ }^{\circ} \mathrm{C}$ for $1 \mathrm{~h}$. To remove unbound phalloidin, coverslips were gently washed twice with $0.5 \mathrm{~mL}$ PBS+ before visualization of the actin filaments with a fluorescence microscope (Leica Microsystem GmbH, Heidelberg, Germany).

\subsubsection{Apoptosis and necrosis staining}

A caspase-3 staining in combination with ethidium monoazide (EMA; Sigma-Aldrich) and counterstaining with Hoechst was performed to examine whether the observed cell morphology changes were associated with apoptosis or necrosis. Activation of caspases plays a central role in apoptosis with caspase- 3 being one of the key effectors. EMA staining was used for the detection of nonviable cells, which can be either apoptotic or necrotic. The Hoechst staining, used as a nucleus staining technique, helped in the determination of cells as apoptotic or necrotic. Macrophages were described as apoptotic when the caspase-3 staining was positive and the EMA staining positive (late apoptosis) or negative (early apoptosis). Necrotic macrophages were negative for caspase-3 but positive for EMA. Normal living cells were negative for both caspase-3 and EMA.

PAM were seeded in a 24 -well plate at $1 \times 10^{6}$ per $\mathrm{mL}$ and incubated at $37{ }^{\circ} \mathrm{C}$ in $5 \% \mathrm{CO}_{2}$ to allow adhesion. After $2 \mathrm{~h}, 0.025 \mu \mathrm{g} / \mathrm{mL}$ of DON was added for $24 \mathrm{~h}$. Cell medium served as negative control. Macrophages exposed to $3 \mu \mathrm{M}$ of staurosporine for $3 \mathrm{~h}$ served as a positive control for apoptosis. For the staining protocol, cells were detached from the well through incubation with $0.3 \mathrm{~mL}$ trypsine for $10 \mathrm{~min}$ and pooled in a falcon tube together with the supernatant. After centrifugation ( $7 \mathrm{~min}, 365 \mathrm{~g}$ ), the cells were resuspended in $0.5 \mathrm{~mL}$ of ice-cold PBS. After another centrifugation step, the supernatant was prelevated and the pellet was resuspended in $0.5 \mathrm{~mL}$ of ice-cold EMA (1:20 in PBS). After an incubation step in the dark for $20 \mathrm{~min}$, the falcon tubes were put under a light bulb during $10 \mathrm{~min}$ after which they were centrifuged ( $7 \mathrm{~min}, 365 \mathrm{~g}$ ). After removal of the supernatant, the cells were fixed by resuspending the pellet in $0.5 \mathrm{~mL}$ paraformaldehyde $3 \%(\mathrm{w} / \mathrm{v})$ in PBS for $10 \mathrm{~min}$ at room temperature. After a centrifugation $(7 \mathrm{~min}$, $365 \mathrm{~g}$ ) and washing step with $0.5 \mathrm{~mL}$ PBS, the cells were permeabilized by incubating in $0.1 \mathrm{~mL}$ Triton$\mathrm{X} 0.1 \%$ for $2 \mathrm{~min}$ followed by the addition of $0.9 \mathrm{~mL}$ PBS. From this point on, PBS was supplemented with $20 \%$ FCS to prevent the cells from sticking to the tube wall. Again, the cells were centrifuged followed by the addition of $0.1 \mathrm{~mL}$ of rabbit antiactive caspase-3 (Sigma-Aldrich) diluted 1:100 in PBS. After $1 \mathrm{~h}$ incubation at $37^{\circ} \mathrm{C}$, the cells were cen- trifuged, washed with PBS and afterwards $0.1 \mathrm{~mL}$ of goat anti-rabbit FITC (1:50 in PBS) (Sigma-Aldrich) was added. The cells were incubated at $37^{\circ} \mathrm{C}$, protected from light, for $1 \mathrm{~h}$. After centrifugation and washing in $0.5 \mathrm{~mL}$ PBS, the cells were counterstained with Hoechst (1 mg/mL, 1/100 dilution in PBS) for $15 \mathrm{~min}$ protected from light. After a centrifugation step (7 min, $365 \mathrm{~g}$ ) and a washing step with PBS, the remaining pellet was resuspended in $20-40 \mu \mathrm{L}$ of PBS and $10 \mu \mathrm{L}$ was mounted in a small drop of mounting medium (DABCO-glycerine). The cells were observed with a fluorescence microscope.

\subsection{Statistical analysis}

All experiments were conducted in triplicate with three repeats per experiment, unless otherwise noted. The data were analyzed using ANOVA to address the significance of difference between mean values with significance set at $p<0.05$.

\section{RESULTS}

\subsection{Low DON concentrations do not affect macrophage viability}

The possible direct cytotoxic effect of DON on PAM at concentrations ranging from 0.005 to $50 \mu \mathrm{g} / \mathrm{mL}$ as determined by the WST-1 assay is shown in Figure 1. DON had no significant effect at concentrations $\leq 0.100 \mu \mathrm{g} / \mathrm{mL}$. At $0.250 \mu \mathrm{g} / \mathrm{mL}, \mathrm{DON}$ had a significant cytotoxic effect of $85 \pm 5 \%(p<0.05)$ after $24 \mathrm{~h}$ of incubation. Concentrations of DON $>0.250 \mu \mathrm{g} / \mathrm{mL}$ showed a cytotoxicity of more than $97 \%$ $(p<0.05)$. The cytotoxicity determined by the LDH test was similar to the previous results (data not shown). Based on these results, only non-cytotoxic concentrations of DON $(<0.250$ $\mu \mathrm{g} / \mathrm{mL})$ were used in the further experiments.

\subsection{High concentrations of DON increase SPI-1 and SPI-2 expression of Salmonella Typhimurium}

Concentrations of DON from 0.005 to $50 \mu \mathrm{g} / \mathrm{mL}$ did not have any effect on the growth of Salmonella Typhimurium WT (data not shown). 


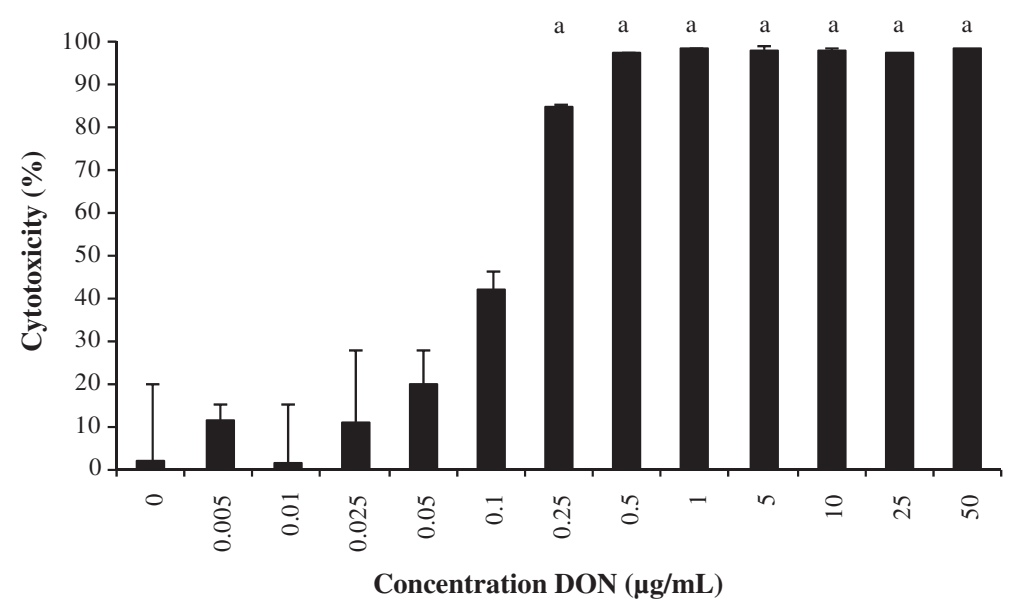

Figure 1. Percentage cytotoxicity in porcine macrophages exposed to DON at 0.005 to $50 \mu \mathrm{g} / \mathrm{mL}$. Twentyfour hours later, the cytotoxic effect was determined by WST-1 assay. Results represent the means of three independent experiments conducted in triplicate and their standard deviation. Superscript (a) refers to a significantly higher cytotoxic effect compared to the unexposed control wells $(p<0.05)$.

High concentrations of DON $(\geq 5 \mu \mathrm{g} / \mathrm{mL})$ in LB medium significantly increased the expression of hilA and $\operatorname{ssr} A$, which are regulators required for the expression of respectively the SPI-1 invasion genes or SPI-2 genes necessary for the intracellular replication and systemic infection of Salmonella Typhimurium $(p<0.05)$. The results are shown in Figure 2.

\subsection{DON promotes the uptake of Salmonella Typhimurium in porcine macrophages}

The results of the invasion and proliferation test of Salmonella Typhimurium WT in PAM with or without prior exposure to DON are summarized in Figure 3A. Uptake was higher in the PAM exposed to $0.025 \mu \mathrm{g} / \mathrm{mL}$ of DON compared to the PAM that were not exposed to $\mathrm{DON}(p<0.05)$, with an average increase factor of 1.45. Similar results were obtained using the deletion mutant $\operatorname{sip} B$ (Fig. 3B). Intracellular replication, represented by $\log \mathrm{cfu} / \mathrm{mL}$ after proliferation minus $\log \mathrm{cfu} / \mathrm{mL}$ after invasion in porcine macrophages, of Salmonella Typhimurium WT in porcine macrophages whether or not exposed to $0.025 \mu \mathrm{g} / \mathrm{mL}$ of DON did not differ significantly $(0.48 \pm 0.339$ versus $0.91 \pm 0.529$ respectively).
The enhanced uptake of Salmonella Typhimurium in PAM exposed to $0.025 \mu \mathrm{g} / \mathrm{mL}$ of DON was confirmed in an invasion and proliferation assay with gfp-Salmonella. The results of this experiment are summarized in Table I. Macrophages exposed to $0.025 \mu \mathrm{g} /$ $\mathrm{mL}$ of DON were more frequently infected by Salmonella Typhimurium in comparison with the control PAM resulting in a higher bacterial count (average 3.9 versus 2.7 bacteria per macrophage, respectively) and a consequent higher number of bacteria in the PAM after $6 \mathrm{~h}$. The proliferation rate of intracellular bacteria however, did not differ significantly between the control and the DON-treated macrophages (2.8 versus 2.6 respectively).

\subsection{DON causes morphological alterations and $\mathrm{F}$-actin reorganization in porcine macrophages by activation of ERK1/2}

PAM were stained with Haemacolor after exposure to $0.025 \mu \mathrm{g} / \mathrm{mL}$ of DON for an incubation time of $24 \mathrm{~h}$. This staining technique was used to test the hypothesis that DON alters the cell morphology and more specifically induces changes in the cell membranes which might result in an enhanced uptake of Salmonella 


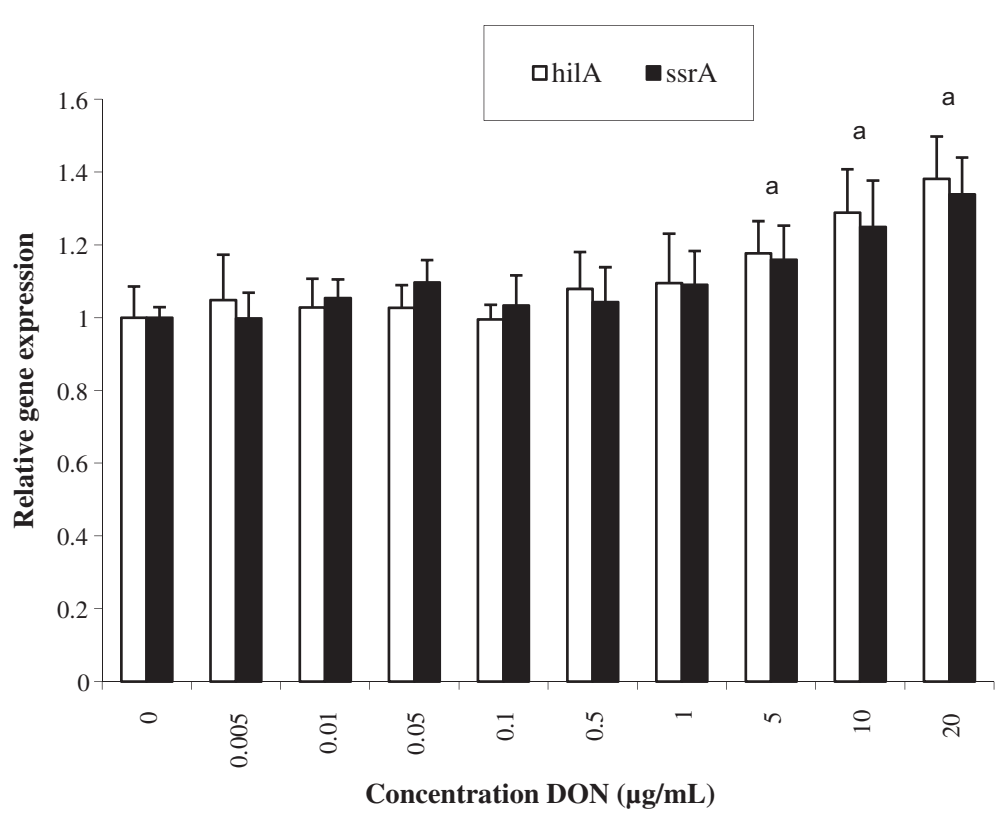

Figure 2. The expression of hilA and ssrA in Salmonella Typhimurium grown in LB medium supplemented with different concentrations of DON. The light production was measured every 15 min during $24 \mathrm{~h}$ and is expressed as the relative gene expression. The results represent the means of three independent experiments conducted in triplicate and their standard deviation. Superscript (a) refers to a significantly higher expression of hilA and ssrA compared to the unexposed control wells $(p<0.05)$.

Typhimurium WT. DON caused marked morphological alterations as the majority of the PAM showed ruffling of the cell (Fig. 4). To examine the actin cytoskeleton, phalloidin was used as a specific probe for polymerized $(\mathrm{F})$ actin. Macrophages exposed to $0.025 \mu \mathrm{g} / \mathrm{mL}$ of DON showed some marked morphological changes compared with the non exposed controls. Macrophages incubated with $0.025 \mu \mathrm{g} / \mathrm{mL}$ of DON for $24 \mathrm{~h}$ demonstrated increased formation of ruffling membranes in $78.5 \pm 2.26 \%$ of the macrophages in comparison with the control macrophages $(10.3 \pm 3.79 \%)$ (Figs. 4C and 4D).

In order to investigate whether the cytoskeletal rearrangements of macrophages after exposure to $0.025 \mu \mathrm{g} / \mathrm{mL}$ of DON, were due to the activation of the MAPK pathway, and more specifically ERK1/2, the actin staining experiment was repeated with on the one hand, DON in combination with the ERK $1 / 2$ inhibitor U0126 ethanolate, and on the other hand PMA, which is an ERK1/2 activator.
Macrophages incubated with $10 \mu \mathrm{M}$ U0126 ethanolate in combination with $0.025 \mu \mathrm{g} / \mathrm{mL}$ of DON, for $24 \mathrm{~h}$, showed a normal F-actin distribution. Only $11.0 \pm 2.00 \%$ of the macrophages demonstrated ruffling membranes. Macrophages incubated with $50 \mathrm{ng} / \mathrm{mL}$ of PMA for $24 \mathrm{~h}$ demonstrated increased formation of ruffling membranes in $97.3 \pm 2.52 \%$ of the macrophages in comparison with the control macrophages (Figs. 4E and 4F) and macrophages treated with U0126 ethanolate (data not shown). These results suggest that the increased membrane ruffling, caused by DON, is due to the activation of ERK1/2.

\subsection{DON induced cell morphology changes are not associated with cellular apoptosis and necrosis}

To determine the cellular apoptosis and necrosis of PAM exposed to $0.025 \mu \mathrm{g} / \mathrm{mL}$ of DON during $24 \mathrm{~h}$, the EMA, caspase- 3 and 

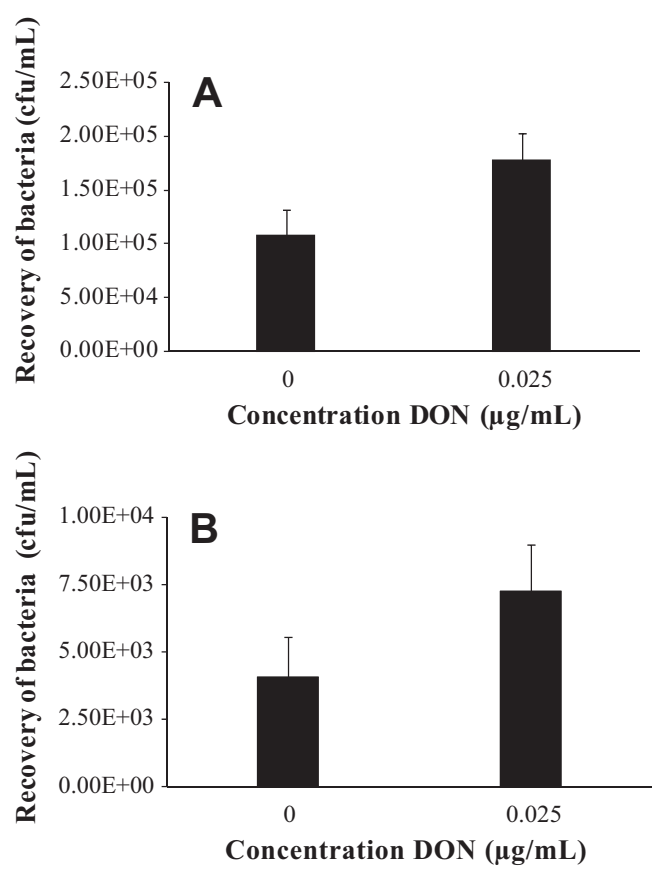

Figure 3. The invasiveness of Salmonella Typhimurium WT (A) and its isogenic $\Delta \mathrm{SipB}$ (B) in porcine pulmonary macrophages whether or not exposed to $0.025 \mu \mathrm{g} / \mathrm{mL}$ of DON is shown. The number of gentamicin-protected bacteria is shown. The results show a representative of three independent experiments conducted in sixfold \pm standard deviation for Salmonella Typhimurium WT and of two independent experiments conducted in sixfold \pm standard deviation for the deletion mutant in SipB.

Hoechst staining were examined in 100 macrophages on three independent occasions.

No significant difference was seen between the PAM exposed to $0.025 \mu \mathrm{g} / \mathrm{mL}$ of DON and the control PAM which indicates that this concentration does not induce apoptosis nor necrosis. The results of this experiment are summarized in Table II.

\section{DISCUSSION}

DON and salmonellosis are emerging issues causing serious problems in the European pig
Table I. Results of the invasion and proliferation assay performed with gfp-producing Salmonella. The results show a representative of two independent experiments conducted in threefold. The number of cell-associated bacteria was counted in 100 macrophages. The results represent the mean bacterial count per macrophages \pm standard error of the mean (sem) after invasion $(0 \mathrm{~h})$ and after proliferation $(6 \mathrm{~h})$, as well as the proliferation rate.

\begin{tabular}{lccc}
\hline & \multicolumn{2}{c}{$\begin{array}{c}\text { Mean bacterial } \\
\text { count } \pm \text { sem }\end{array}$} & $\begin{array}{c}\text { Proliferation } \\
\text { rate }\end{array}$ \\
\hline PAM & $0 \mathrm{~h}$ & $6 \mathrm{~h}$ & \\
Control & $2.7 \pm 0.11$ & $7.6 \pm 0.35$ & 2.8 \\
0.025 & $3.9 \pm 0.13$ & $10.1 \pm 0.39$ & 2.6 \\
$\mu \mathrm{g} / \mathrm{mL}$ DON & & & \\
\hline
\end{tabular}

industry. The toxic effects of the mycotoxin DON have been well documented in several animal species and in diverse cell culture experiments. Several publications indicate that the presence of this Fusarium mycotoxin in feed can seriously affect the health status of pigs and other animals [16, 28, 30]. Salmonella Typhimurium is the predominant serovar isolated from pigs in Europe and since pigs may be subclinically infected, they are an important threat to both animal and human health. Although DON and Salmonella can be commonly encountered in the pig industry, this is the first report describing an interaction between DON and the pathogenesis of a Salmonella Typhimurium infection in pigs.

Concentrations of DON higher than $0.1 \mu \mathrm{g} / \mathrm{mL}$ had a significant cytotoxic effect on porcine macrophages after $24 \mathrm{~h}$ of exposure. These results correspond with the literature where DON was described to inhibit the proliferation of Caco-2 cells in a dose dependent manner, with a significant effect appearing at $0.2 \mu \mathrm{g} / \mathrm{mL}$ [31]. Bimczok et al. [1], however, described that DON only had a significant cytotoxic effect on monocyte-derived dendritic cells at $0.8 \mu \mathrm{g} / \mathrm{mL}$. To eliminate a possible cytotoxic effect of DON on the porcine macrophages, we chose to work with concentrations of DON below $0.1 \mu \mathrm{g} / \mathrm{mL}$ in the further experiments. These low concentrations are relevant in practice since in several publications, depending 

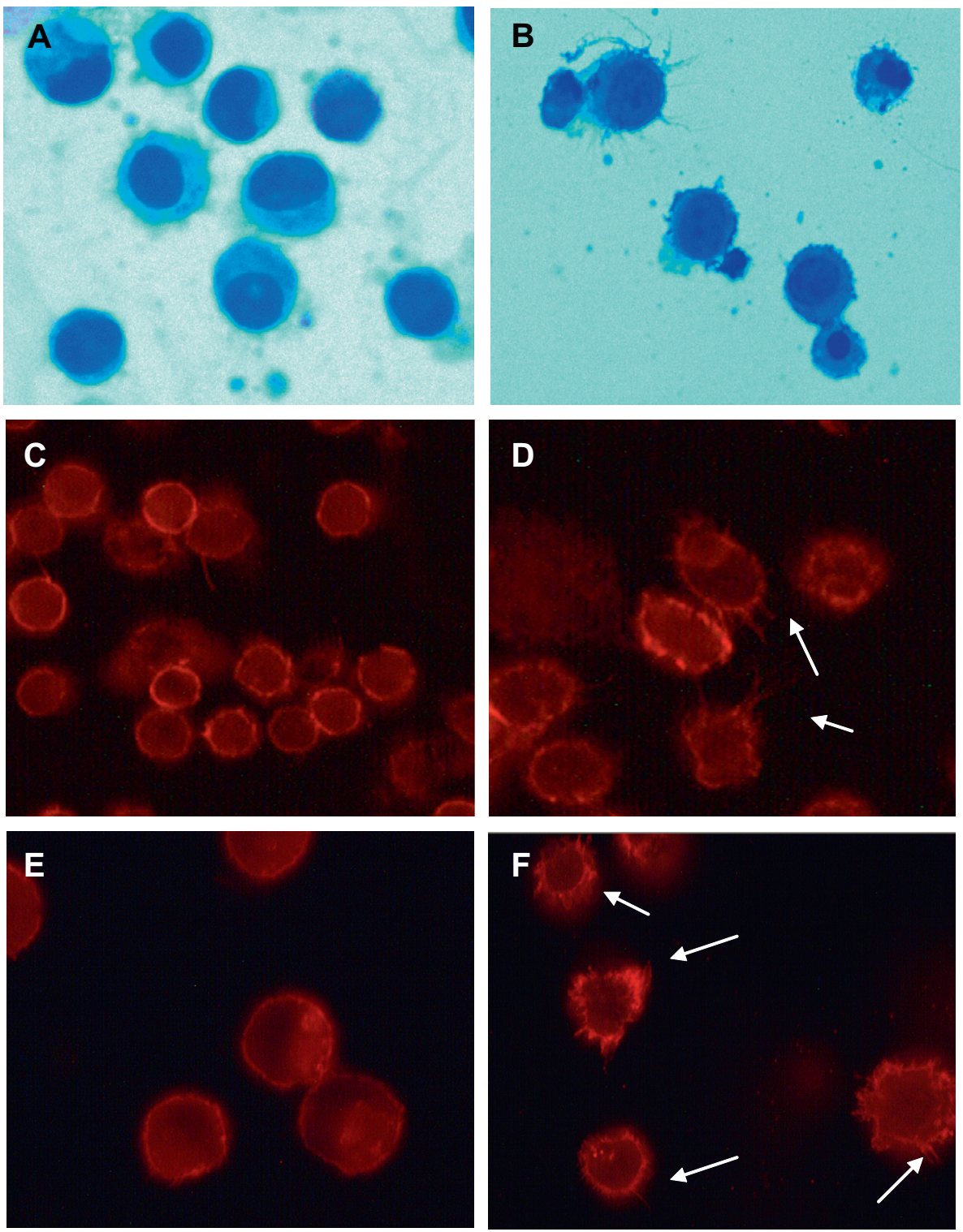

Figure 4. Haemacolor staining of PAM whether or not exposed to $0.025 \mu \mathrm{g} / \mathrm{mL}$ of DON. Figure A shows porcine macrophages not exposed to DON, whereas Figure B shows DON exposed macrophages with marked membrane ruffling. Figures $\mathrm{C}-\mathrm{F}$ show fluorescence microscopic pictures of actin filament arrangement in PAM either treated with cell medium, $0.025 \mu \mathrm{g} / \mathrm{mL}$ of DON, $10 \mu \mathrm{M}$ of the ERK1/2 inhibitor U0126 ethanolate in combination with $0.025 \mu \mathrm{g} / \mathrm{mL}$ of DON or with $50 \mathrm{ng} / \mathrm{mL}$ of the ERK1/2 activator PMA, for $24 \mathrm{~h}$. Control macrophages (C) and macrophages exposed to U0126 ethanolate in combination with DON (E) demonstrated a normal distribution of F-actin. DON (D) and PMA (F) exposed macrophages demonstrated increased formation of membrane ruffles (indicated by white arrows). (A color version of this figure is available at www.vetres.org.) 
Table II. Results of the apoptosis and necrosis staining of PAM whether or not exposed to $0.025 \mu \mathrm{g} / \mathrm{mL}$ of DON. The results represent the average percentage of cells showing apoptosis or necrosis and their standard deviation. Normal cells are negative for both EMA and caspase-3, necrotic cells are positive for EMA but negative for caspase-3, apoptotic cells are always positive for caspase-3 but can be EMA positive (late apoptosis) or negative (early apoptosis).

\begin{tabular}{lccc}
\hline & \multicolumn{3}{c}{ Average percentage (\%) of cells \pm sd } \\
\hline PAM & Normal & Apoptosis & Necrosis \\
Control & $80.7 \pm 6.66$ & $19.3 \pm 6.66$ & $0 \pm 0$ \\
$0.025 \mu \mathrm{g} / \mathrm{mL}$ DON & $76.3 \pm 5.03$ & $21.0 \pm 5.00$ & $2.7 \pm 2.08$ \\
\hline
\end{tabular}

on the dietary content of DON, serum concentrations of DON varying from 0.013 to $0.026 \mu \mathrm{g} / \mathrm{mL}$ were measured in pigs $[9,19]$.

The growth of Salmonella Typhimurium was not affected by concentrations of DON up to $50 \mu \mathrm{g} / \mathrm{mL}$. Nevertheless, high concentrations of DON ( $\geq 5 \mu \mathrm{g} / \mathrm{mL})$ in LB medium, significantly increased the expression of hilA and ssrA. Although this is an interesting observation, concentrations of $5 \mu \mathrm{g} / \mathrm{mL}$ of DON are exceptional contamination levels under field conditions and hence not relevant for the in vivo situation.

Preexposure of macrophages to concentrations of DON, as low as $0.025 \mu \mathrm{g} / \mathrm{mL}$ during $24 \mathrm{~h}$, enhanced the susceptibility of macrophages for the uptake of Salmonella Typhimurium in the macrophages. On average, the colony forming units per $\mathrm{mL}$ were $150 \%$ higher compared to control macrophages. This was confirmed by microscopic evaluation using gfp-Salmonella. Since $0.025 \mu \mathrm{g} / \mathrm{mL}$ of DON was proven not to affect the expression of SPI-1 and SPI-2 genes of Salmonella Typhimurium, the observed enhanced uptake might be caused by changes in the cell morphology. This hypothesis is also supported by the results of the invasion test with the $\Delta \mathrm{SipB}$ strain which gave similar results as the WT strain, indicating that the enhanced uptake seen after exposure of the PAM to DON, is not SPI-1 associated.

Salmonella entry in host cells involves a complex series of actin cytoskeletal changes [20]. When we examined the cell morphology focusing on the cell membrane changes, we saw marked changes in DON-treated porcine macrophages compared to non treated controls. Macrophages exposed to $0.025 \mu \mathrm{g} / \mathrm{mL}$ of DON demonstrated alterations of the cell membrane on Haemacolor staining. Special attention was paid on the ruffling of the cell membrane as this is a cytoskeletal change that is commonly described with the entry of Salmonella Typhimurium in the macrophages. Therefore, staining with phalloidin-Texas Red ${ }^{\circledR}$, as specific probe for polymerized actin, was performed which clearly indicated a reorganization of $\mathrm{F}$-actin and formation of membrane ruffles.

ERK1/2, a MAPK, is activated both by trichothecenes such as DON via a process termed the 'ribotoxic stress response' and by the invasion of Salmonella Typhimurium in macrophages [29, 39]. Recently, Yang et al. [37] described that DON induces p21 mRNA stability in human epithelial cells in terms of interactions RNA-binding proteins via ERK 1/2 activation. Since the PAK and the Rho-family of small GTP'ases play a central role in both actin dynamics, membrane ruffling and Salmonella induced invasion, p21 mRNA stabilization might explain the changes in the cell membrane morphology seen in macrophages exposed to $0.025 \mu \mathrm{g} / \mathrm{mL}$ of DON and might account for the enhanced uptake of Salmonella Typhimurium in porcine macrophages preexposed to DON.

To test the hypothesis that the modulations of the cytoskeleton in macrophages, caused by DON, are due to the activation of ERK1/2, staining with phalloidin-Texas $\operatorname{Red}^{\circledR}$ was performed in macrophages after preexposure to an ERK1/2 activator (PMA) or an ERK1/2 inhibitor (U0126 ethanolate) in combination with $0.025 \mu \mathrm{g} / \mathrm{mL}$ of DON.

U0126 ethanolate inhibited the morphological rearrangements in macrophages that were 
exposed to DON, whereas PMA caused an increased formation of membrane ruffles. Moreover, PMA and DON-treated macrophages have a similar morphology. These results suggest that the increased membrane ruffling, caused by DON, is due to the activation of ERK1/2.

In conclusion, we have shown that low concentrations of DON could modulate the cytoskeleton of macrophages through ERK1/2 F-actin reorganization resulting in an enhanced uptake of Salmonella Typhimurium in porcine macrophages.

Acknowledgements. Prof. Dr Ivan Rychlik has been supported by the project MZE0002716201 of the Czech Ministry of Agriculture. The pFPV25.1 plasmid was a kind gift of Prof. Dr Brett Finlay. The assistance of Rosalie Devloo is gratefully appreciated. This work was supported by the Institute for the Promotion of Innovation by Science Technology in Flanders (IWT Flanders), Brussels, Belgium (project070574).

\section{REFERENCES}

[1] Bimczok D., Döll S., Rau H., Goyarts T., Wundrack N., Naumann M., et al., The Fusarium toxin deoxynivalenol disrupts phenotype and function of monocyte-derived cendritic cells in vivo and in vitro, Immunobiology (2007) 212:655-666.

[2] Böhm J., The significance of the mycotoxins deoxynivalenol, zearalenone and ochratoxin A for agricultural domestic animals, Arch. Tierernahr. (1992) 42:95-111 (in German).

[3] Bokoch G.M., Biology of the p21-activated kinases, Annu. Rev. Biochem. (2003) 72:743-81.

[4] Bottalico A., Perrone G., Toxigenic Fusarium species and mycotoxins associated with head blight in small-grain cereals in Europe, Eur. J. Plant Pathol. (2002) 108:611-624.

[5] Boyen F., Pasmans F., Donné E., Van Immerseel F., Adriaensen C., Hernalsteens J.-P., et al., Role of SPI-1 in the interaction of Salmonella Typhimurium with porcine macrophages, Vet. Microbiol. (2006) 113:35-44.

[6] Boyen F., Pasmans F., Van Immerseel F., Morgan E., Botteldoorn N., Heyndrickx M., et al., A limited role for SsrA/B in persistent Salmonella Typhimurium infections in pigs, Vet. Microbiol. (2008) 128:364-373.

[7] Boyen F., Haesebrouck F., Maes D., Van Immerseel F., Ducatelle R., Pasmans F., Non-typhoidal
Salmonella infections in pigs: a closer look at epidemiology, pathogenesis and control, Vet. Microbiol. (2008) 130:1-19.

[8] Cole R.A., Cox R.H., Handbook of toxic fungal metabolites, Academic Press, New York, 1981.

[9] Dänicke S., Goyarts T., Döll S., Grove N., Spolders M., Flachowsky G., Effects of the Fusarium toxin deoxynivalenol on tissue protein synthesis in pigs, Toxicol. Lett. (2006) 165:297-311.

[10] Das D., Pintucci G., Stern A., MAPK-dependent expression of p21(WAF) and p27(kip1) in PMAinduced differentiation of HL60 cells, FEBS Lett. (2000) 472:50-52.

[11] Döll S., Dänicke S., In vivo detoxification of Fusarium toxins, Arch. Anim. Nutr. (2004) 58: 419-441.

[12] Dom P., Haesebrouck F., De-Baetselier P., Stimulation and suppression of the oxygenation activity of porcine pulmonary alveolar macrophages by Actinobacillus pleuropneumoniae and its metabolites, Am. J. Vet. Res. (1992) 53:1113-1118.

[13] Donné E., Pasmans F., Boyen F., Van Immerseel F., Adriaensen C., Hernalsteens J.-P., et al., Survival of Salmonella serovar Typhimurium inside porcine monocytes is associated with complement binding and suppression of the production of reactive oxygen species, Vet. Microbiol. (2005) 107:205-214.

[14] Favata M.F., Horiuchi K.Y., Manos E.J., Daulerio A.J., Stradley D.A., Feeser W.S., et al., Identification of a novel inhibitor of mitogen-activated protein kinase kinase, J. Biol. Chem. (1998) 273:18623-18632.

[15] Fedorka-Cray P.J., Gray J.T., Way C., Salmonella infections in pigs, in: Wray C., Wray A. (Eds.), Salmonella in domestic animals, CAB International, Wallingford, 2000, pp. 191-207.

[16] Fink-Gremmels J., Mycotoxins: their implications for human and animal health, Vet. Q. (1999) 21:115-120.

[17] Finlay B.B., Ruschkowski S., Dedhar S., Cytoskeletal rearrangements accompanying Salmonella entry into epithelial cells, J. Cell Sci. (1991) 99:283-296.

[18] Fukata T., Sasai K., Baba E., Arakawa A., Effect of ochratoxin A on Salmonella Typhimurium-challenged layer chickens, Avian Dis. (1996) 40:924-926.

[19] Goyarts T., Dänicke S., Tiemann U., Rothkötter H.-J., Effect of the Fusarium toxin deoxynivalenol (DON) on $\operatorname{IgA}, \operatorname{IgM}$ and $\operatorname{IgG}$ concentrations and proliferation of porcine blood lymphocytes, Toxicol. In Vitro (2006) 20:858-867. 
[20] Guiney D.G., Lesnick M., Targeting of the actin cytoskeleton during the infection by Salmonella strains, Clin. Immunol. (2005) 114:248-255.

[21] Hara-Kudo Y., Sugita-Konishi Y., Kasuga F., Kumagai S., Effects of deoxynivalenol on Salmonella enteritidis infection, Mycotoxins (1996) 42:51-55.

[22] Haschek W.M., Voss K.A., Beasley V.R., Selected mycotoxins affecting animal and human health, in: Handbook of Toxicological Pathology, Academic Press, London, 2002, pp. 645-699.

[23] Lundberg U., Vinatzer U., Berdnik D., von Gabain A., Baccarini M., Growth phase-regulated induction of Salmonella-induced macrophages apoptosis correlates with transient expression of SPI-1 genes, J. Bacteriol. (1999) 181:3433-3437.

[24] Marcus S.L., Brumell J.H., Pfeifer C.G., Finlay, B., Salmonella pathogenicity islands: big virulence in small packages, Microbes Infect. (2000) 2:145-156.

[25] Monack D.M., Raupach B., Hromockyi A.E., Falkow S., Salmonella Typhimurium invasion induces apoptosis in infected macrophages, Proc. Natl. Acad. Sci. USA (1996) 93:9833-9838.

[26] Pestka J.J., Zhou H.R., Moon Y., Chung Y.J., Cellular and molecular mechanism for immune modulation by deoxynivalenol and other trichothecenes: unraveling a paradox, Toxicol. Lett. (2004) 153: 61-73.

[27] Pestka J.J., Mechanisms of deoxynivalenolinduced gene expression and apoptosis, Food Addit. Contam. (2008) 24:1-13.

[28] Pinton P., Accensi F., Beauchamp E., Cossalter A.-M., Callu P., Grosjean F., Oswald I.P., Ingestion of deoxynivalenol (DON) contaminated feed alters the pig vaccinal immune response, Toxicol. Lett. (2008) 177:215-222.

[29] Procyk K.J., Kovarik P., Von Gabain A., Baccarini M., Salmonella Typhimurium and lipopolysaccharide stimulate extracellularly regulated kinase activation in macrophages by a mechanism involving phosphatidylinositol 3-kinase and phospholipase D as novel intermediates, Infect. Immun. (1999) 67: 1011-1017.

[30] Rotter B.A., Prelusky D.B., Toxicology of deoxynivalenol, J. Toxicol. Environ. Health (1996) 48:1-34.
[31] Sergent T., Parys M., Garsou S., Pussemier L., Schneider Y.-J., Larondelle Y., Deoxynivalenol transport across human intestinal $\mathrm{Caco}-2$ cells and its effects on cellular metabolism at realistic intestinal concentrations, Toxicol. Lett. (2006) 164:167-176.

[32] Stoev S.D., Goundasheva D., Mirtcheva T., Mantle P.G., Susceptibility to secondary bacterial infections in growing pigs as an early response in ochratoxicosis, Exp. Toxicol. Pathol. (2000) 52: 287-296.

[33] Tai J.H., Pestka J.J., Impaired murine resistance to Salmonella Typhimurium following oral exposure to the trichothecene T-2 toxin, Food Chem. Toxicol. (1988) 26:691-698.

[34] Trenholm H.L., Prelusky D.B., Young J.C., Miller J.D., Reducing mycotoxins in animals feeds, Agriculture Canada Publication 1827E. Communications Branch, Agriculture Canada, Ottawa, 1988.

[35] Valdivia R.H., Falkow S., Bacterial genetics by flow cytometry: rapid isolation of Salmonella Typhimurium acid-inducible promoters by differential fluorescence induction, Mol. Microbiol. (1996) 22:367-378.

[36] Van Immerseel F., De Buck J., Boyen F., Bohez L., Pasmans F., Sevcik M., et al., Medium-chain fatty acids decrease colonization and invasion through hilA suppression shortly after infection of chickens with Salmonella enteric serovar Enteritidis, Appl. Environ. Microbiol. (2004) 70:3582-3587.

[37] Yang H., Chung D.H., Kim Y.B., Choi Y.H., Moon Y., Ribotoxic mycotoxin deoxynivalenol induced $\mathrm{G} 2 / 3$ cell cycle arrest via $\mathrm{p} 21^{\mathrm{Cip} / \mathrm{WAF} 1} \mathrm{mRNA}$ stabilization in human epithelial cells, Toxicology (2008) 243:145-154.

[38] Zhou H.R., Lau A.S., Pestka J.J., Role of double stranded RNA-activated protein kinase R (PKR) in deoxynivalenol-induced ribotoxic stress response, Toxicol. Sci. (2003) 74:335-344.

[39] Zhou H.R., Jia Q., Pestka J.J., Ribotoxic stress response to the trichothecene deoxynivalenol in the macrophage involves the SRC family kinase Hck, Toxicol. Sci. (2005) 85:916-926. 